\title{
Оценка почвенных условий Крымского полуострова применительно к культуре винограда
}

Евгений Александрович Рыбалко, канд. с.-х. наук, зав. сектором агроэкологии, email: rybalko_ye_a@mail.ru; Наталья Валентиновна Баранова, канд. с.-х. наук, вед. науч. сотр. сектора агроэкологии, email: natali.v.0468@mail.ru; Виктория Юрьевна Борисова, агроном сектора агроэкологии, email: borisova.12@mail.ru Федеральное государственное бюджетное учреждение науки «Всероссийский национальный научно-исследовательский институт виноградарства и виноделия «Магарач» РАН», Россия, Республика Крым, 298600, г. Ялта, ул. Кирова, 31

Проведена оценка почвенных ресурсов Крымского полуострова применительно к культуре винограда. Разнообразные типы почв Крымского полуострова были объединены в пять групп по степени пригодности для виноградного растения. Создана крупномасштабная векторная карта бонитета почв для винограда. В работе использованы картографические материалы по Крымскому полуострову, составленные Крымской землеустроительной экспедицией Республиканского проектного института «Укрземпроект» масштаба 1:200 000. Оцифровка карт, анализ пространственного распределения почвенных типов с различными бонитировочными оценками и расчёт их площадей проводились с использованием географических информационных систем. Установлено, что на Крымском полуострове общая площадь обследованных почв составляет 2233,0 тыс. га. Высокий бонитет применительно к винограду у черноземов предгорных выщелоченных на разных породах (91-100 баллов), черноземов южных слабогумусированных, в том числе мицелярно-высококарбонатных, черноземов на плотных глинах, черноземов карбонатных на элювии и делювии карбонатных пород, черноземов преимущественно карбонатных щебневатых и галечных на элювии плотных и галечных карбонатных и окарбоначенных пород, черноземов предгорных на плотных карбонатных породах, коричневых горных карбонатных и некарбонатных почв (81-90 баллов). Почвы с оценкой 60 и менее балов малопригодны или вообще непригодны для получения высококачественного винограда. В данную категорию попали засолённые переувлажнённые и маломощные почвы. Они составляют 26,7\%, от общей площади обследованных территорий. 73,4\% земель пригодны для ведения промышленной культуры винограда, ориентированной на получение высококачественной продукции. Наиболее благоприятные почвенные условия для развития виноградарства сложились в Южнобережной зоне, центральной части предгорного района, центральных степных, западных и юго-западных районах Крымского полуострова. В прибрежной северной, северо-восточной частях, на отдельных участках предгорных районов южной и юго-западной частей Крымского полуострова, а также на значительных массивах Керченского полуострова сложились неблагоприятные почвенные условия, лимитирующие эффективное выращивание промышленной культуры винограда.

Ключевые слова: почвенно-климатических условия; виноград; почва; бонитет почв; типы почв.

$\mathrm{B}$ ведение. Важной частью агропромышленного комплекса Крыма явмяется виноградарство. ОАним из важных звеньев повышения продуктивности насажАений явмяется размещение виноградников в оптимальных почвенно-кАиматических условиях.

\section{R I G I N A L R E S E A R C H}

\section{Assessment of the Crimean peninsula soil conditions in the context of viticulture}

Yevgeniy Aleksandrovich Rybalko, Natalia Valentinovna

Baranova, Viktoriya Yuryevna Borisova

Federal State Budget Scientific Institution All-Russian National

Research Institute of Viticulture and Winemaking Magarach, Russian Academy of Sciences, 31 Kirov Str., 298600 Yalta, Republic of Crimea, Russian Federation

Soil resources of the Crimean Peninsula were assessed for their suitability for vine growing. Various soil types of the Crimean Peninsula were divided into five groups by the degree of their suitability for a grapevine plant. A large-scale vector map of soil bonitet for grapevine was created. The study used cartographic data on the Crimean Peninsula at a scale of 1:200 000 compiled by the Crimean land use planning expedition of the Republican Design Institute Ukrzemproekt. Maps digitization, analysis of soil types spatial distribution with various land quality assessments and their area calculation was done using geographic information systems. The total area of surveyed soils in Crimea made 2233.0 thousand ha. High bonitet with regards to grapevine growing was established for piedmont chernozems leached on different rocks (91-100 points), southern slightly humic chernozems, including micellar-high carbonate chernozems, dense clay chernozems, carbonate chernozems on eluvium and carbonate diluvium rocks, predominantly carbonate rubbly and pebble chernozems on eluvium of dense and pebble carbonate and carbonaceous rocks, foothill chernozems on dense carbonate rocks, brown mountain carbonate and non-carbonate soils (81-90 points). Soils that received 60 or less points are hardly or not at all suitable for the production of high-quality grapes. Saline, waterlogged and thin soils fell into this category. They made up 26.7\% of the total surveyed area. $73.4 \%$ of the land is suitable for industrial viticulture and can produce high-quality produce. The South Coast zone, central part of the piedmont region, central steppe, western and southwestern regions of the Crimean Peninsula have the most favorable soil conditions for viticulture development. The coastal north, north-eastern parts, some parts of the foothill areas of the southern and south-western parts of the Crimean Peninsula, as well as significant areas of the Kerch Peninsula developed unfavorable soil conditions limiting effective industrial viticulture.

Key words: soil and climatic conditions; grapevine; soil; soil bonitet; soil types.

Наукой и практикой Аоказано, что Аця обоснования закладки и возделывания сортовых виноградников, необходима комплексная оценка 5 основных факторов, обуславливающих успешное развитие виноградарства: климатические условия, свойства почвы, орографические условия местности, сортовая особенность вино-

\section{Как цитировать эту статью:}

Рыбалко Е.А., Баранова Н.В., Борисова В.Ю. Оценка почвенных условий крымского полуострова применительно к культуре винограда. // «Магарач». Виноградарство и виноделие, 2019; 21(3); С. 235-239. DOI 10.35547/IM.2019.21.3.009

\section{How to cite this article:}

Rybalko Ye.A., Baranova N.V., Borisova V.Yu. Assessment of the Crimean peninsula soil conditions in the context of viticulture. Magarach. Vinogradarstvo $i$ Vinodelie = Magarach. Viticulture and Winemaking, 2019; 21(3):235-239. DOI 10.35547/IM.2019.21.3.009 (in Russian)

удК 634.8.047:631.42:581.542.44(477.75)

Поступила 08.02.2019

Принята к публикации 20.08.2019

(C) Авторы, 2019 
града, специамизация помучаемой продукции [1-3].

На необходимость проведения оценки пригодности земемь Аця выращивания винограда многоцелевого направления использования указывает ряА авторов [4-6].

Анализ почвенных ресурсов Аля развития виноградарства проведен в ПреАгорной провинции Аагестана. В результате подсчитаны площади виноградопригодных почв с определением фондов освоения в разрезе отАельных аАминистративных районов [7].

Ивановым В.A. и Кузнецовой Е.В. обоснована целесообразность оценки качества почв как среАства производства, главным образом, растениеводческой продукции. Предлагается принципиально новая методика оценки качества почв, а также приведены конкретные примеры её применения Аля решения размичных заАач и состав ения соответствующих картограмм в цемях разработки приемов рационацьного использования почв [8].

Физиологические особенности виноградного растения позвоцяют располагать его в различных кмиматических зонах и на разцичных почвах. Такая пластичность детерминирована наличием в видовом составе многообразия кмонов и сортов. Направцение испоцьзования в промышленных цемях виноградника, поАбор его сортового состава, в первую очередь, обуслов$\Lambda$ ивают почвенно-кииматические условия местности. В Крыму подобное разнообразие Аает возможность получать винограА и виноматериалы Аля производства высококачественных вин разцичного типа $[9,10]$.

Многие авторы отмечают, что виноградники можно выращивать на разцичных типах и подтипах почв, кроме засоленных, заболоченных и очень тяжемых по гранулометрическому (механическому) составу, но мучшими из них явцяются карбонатные и обыкновенные черноземы слабо- и среднесмытые [11-16].

Вопросами вцияния почвы на развитие и созревание винограда уже много Аесятиметий ученые занимаются за рубежом [17-20].

Во Франции, в провинции Бордо, изучаци влияние типа и температуры почвы, а также препаратов азота на развитие виноградной мозы и винограда [21].

В последнее время возрос интерес к механизмам, с помощью которых та или иная почва виияет на рост винограда, его сортовые характеристики. Исследователи из Португалии Аля определения химических и физических свойств почвы используют такой метод, как бцижняя инфракрасная спектроскопия (NIRS) [22].

В винодецьческих регионах Австрации проведены исследования по оценке полевого прибора ближнего

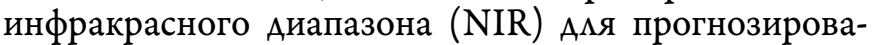
ния содержания минерацьных веществ, $\mathrm{pH}$ и электропроводности в образцах почвы виноградников. Это исследование показало, что можно измерить химические свойства почвы на винограАнике, и основными преимуществами такого подхода будут скорость, низкая стоимость и способность кучше управцять и контролировать плодородие почвы [23].

С помощью ГИС-технологии в Румынии разработана методология определения агрокмиматического потенциала и его пространственного распределения в виноградарских районах. Получена новая, оригинацьная модемь Аля анациза экокмимата виноградарства [24].

Целью исследований являлась оценка степени благоприятности почвенных ресурсов Крыма применительно к культуре винограда.

\section{Материалы и методы.}

В работе использованы картографические материалы по Крымскому полуострову, составленные Крымской землеустроительной экспеАицией Республиканского проектного института «Укрземпроект» масштаба 1:200 000. Оцифровка карт, анамиз пространственного распределения почвенных типов с разАичными бонитировочными оценками и расчёт их площадей проводимись с использованием географических информационных систем.

\section{Результаты исследований}

При агроэкологической оценке почвенных ресурсов объектом оценки выступают почвы, а субъектом - сельскохозяйственные культуры. Специфика этой оценки закмючается в приоритетности выявления уровня потенциацьного плодородия почв и учета его относительного характера, что связано с неодинаковыми требованиями разАичных культур к эдафическим условиям произрастания. ГАавным критерием оценки служат статистические почвенные свойства, коррелятивные с урожайностью растений. В настоящее время разработаны основы потенциацьного плодородия почв Крымского полуострова (в бациах) Аця основных семьскохозяйственных культур Араган Н.А. [9].

При анацизе плодородия почв Крыма Аця винограАного растения, мы использоваци Аанный материам по бонитету почв, а также ранее созданную нами эмектронную векторную карту почв Крыма. Разработанная карта содержит информацию о механическом составе почв, почвообразующих породах, степени засолённости, смытости и Ар. и позволяет осуществцять быстрый анализ почвенно-кмиматических условий в зависимости от требований к качеству конечной проАукции [25].

Разнообразные типы почв Крымского полуострова нами быми объединены в пять групп по степени пригодности Аця винограАного растения (рис.).

1. Почвы с оценкой 91-100 бам ов:

- черноземы предгорные выщелоченные на разных породах, в том числе слабо- и среднесмытые 2,7\%, среднесмытые $1,5 \%$.

2. Почвы бонитета 81-90 баммов:

- черноземы южные слабогумусированные, черноземы южные слабогумусированные, мицелярно-высококарбонатные, в т.ч. слабосмытые 9,6\%, среднесмытые 0,6\%;

- черноземы южные слабогумусированные, мицемярно-карбонатные, в т.ч. слабосмытые $2,6 \%$;

- черноземы на плотных глинах, т.ч. слабосмытые 1,0\%, среднесмытые 0,8\%, симьносмытые 1,3\%;

- черноземы карбонатные на эмювии и Аелювии карбонатных пород;

- черноземы преимущественно карбонатные щебневатые и галечные на эмювии плотных и гамечных 


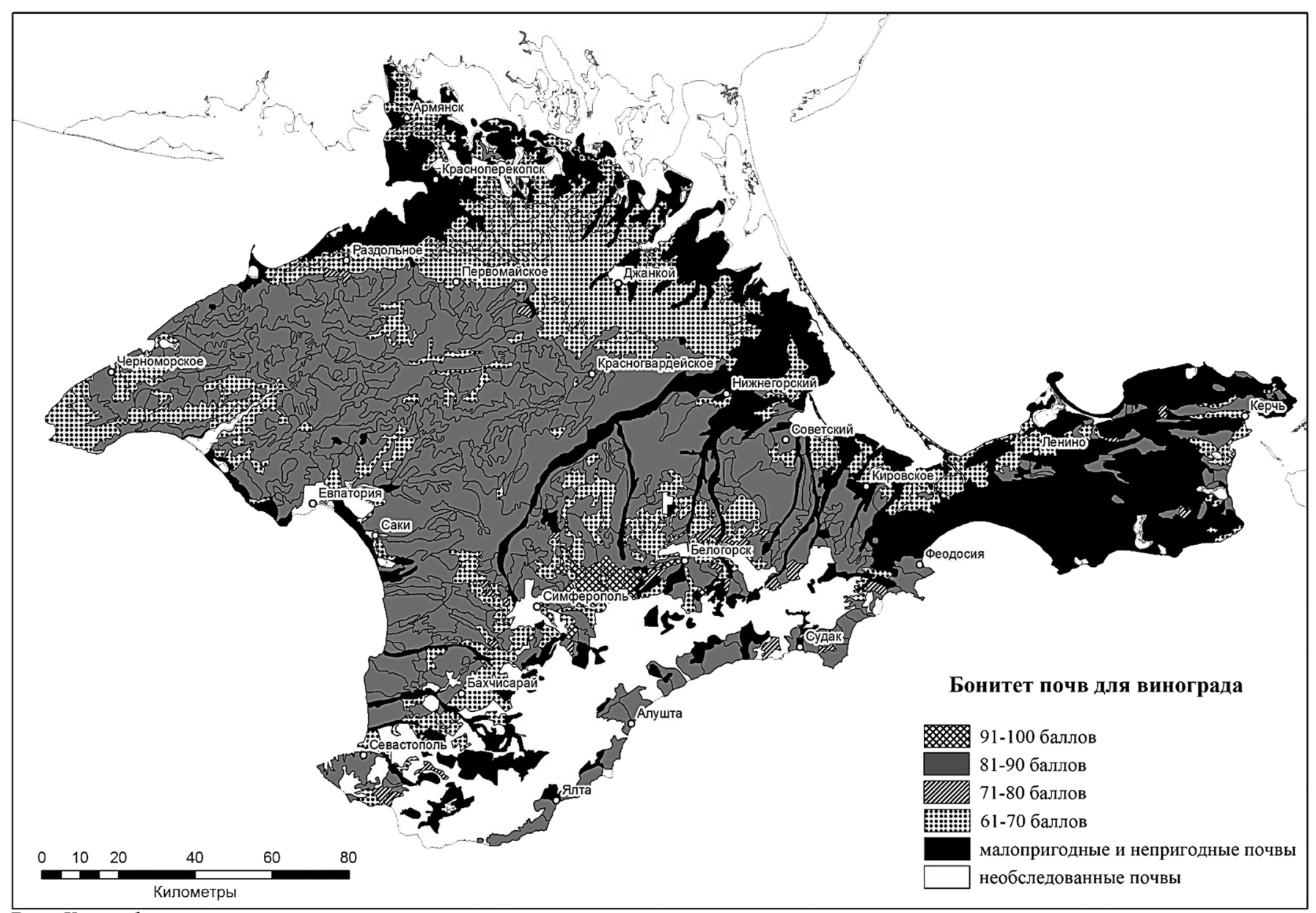

Рис. Карта бонитета почв для винограда

Fig. Soil bonitet map for grapevine

карбонатных и окарбоначенных пород, в т.ч. слабосмытые $15,7 \%$, слабо- и среАнесмытые $31,2 \%$, среднесмытые $6,7 \%$, средне- и сильносмытые $2,2 \%$, сильносмытые 0,8\%;

- черноземы предгорные на плотных карбонатных породах, в т.ч. слабосмытые 6,3\%, слабо- и среднесмытые 5,9\%, среднесмытые 6,0\%, средне- и сильносмытые 4,2\%;

- коричневые горные карбонатные почвы, в том числе слабосмытые 7,8\%, слабо- и среднесмытые $10,0 \%$, среднесмытые $4,3 \%$, средне- и сильносмытые $41,8 \%$;

- коричневые горные некарбонатные почвы, в том числе среднесмытые $38,9 \%$, сильносмытые $35,9 \%$.

3. Почвы бонитета 71-80 бамлов:

- черноземы южные остаточно глубоко-слабосомонцеватые;

- черноземы предгорные солонцеватые преимущественно на пиотных засоменных почвах;

- коричневые горные солонцеватые почвы, в том числе средне- и сильносмытые, $45,7 \%$.

4. Почвы с оценкой 61-70 бамлов:

- черноземы южные слабо- и среднесолонцеватые, в том числе слабосмытые $5 \%$;

- дерновые карбонатные почвы на элювии плотных карбонатных пород, в т. ч. слабосмытые 4,0\%, слабо- и среднесмытые $20,3 \%$, среднесмытые $4,4 \%$, средне- и симьносмытые 2,9\%;

- дерновые почвы на элювии некарбонатных пород, в т. ч. среднесмытые $30,1 \%$, среАне- и сильносмы- тые $38,6 \%$, сильносмытые $31,3 \%$

- темно-каштановые слабо- и среднесолонцеватые почвы, в том числе слабосмытые $3,8 \%$, слабо- и среАнесмытые $1,2 \%$, среднесмытые $1,4 \%$

5. Почвы с оценкой 60 и менее баммов:

- засоленные, переувлажненные и маломощные почвы.

Аля кажАой из выделенных групп рассчитана площаАь и удельный вес в структуре почвенного покрова Крымского полуострова (табц.).

Наиболее высокий бонитет применительно к винограду у черноземов предгорных выщелоченных на разных породах, в том числе слабо- и среднесмытых 2,7\%, среднесмытых 1,5\% (91-100 баммов). Распространены они в центральной части преАгорного района и занмают 0,8 \% от общей площади обследованной

Таблица. Структура почвенного покрова Крымского полуострова по уровню бонитета для винограда

Table. Soil cover structure of the Crimean Peninsula on the level of bonitet for viticulture

\begin{tabular}{|c|c|c|c|}
\hline \multirow{2}{*}{ № } & \multirow{2}{*}{ 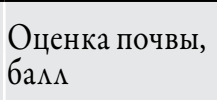 } & \multicolumn{2}{|l|}{ Площадь } \\
\hline & & тыс. га & $\%$ \\
\hline 1 & $91-100$ & 18,0 & 0,8 \\
\hline 2 & $81-90$ & 1037,5 & 46,5 \\
\hline 3 & $71-80$ & 23,0 & 1,0 \\
\hline 4 & $61-70$ & 561,3 & 25,1 \\
\hline 5 & 60 и менее & 593,2 & 26,7 \\
\hline & Bcero & 2233,0 & 100 \\
\hline
\end{tabular}


территории. Из всех почв, пригодных Аһя винограда, наибольший удемьный вес имеют почвы с бонитетом 81-90 баммов, их площадь составмяет 1037,5 тыс. га. Они преобладают в Южнобережной зоне, центрацьных степных, западных и юго-западных районах Крымского полуострова. Почвы бонитета 71-80 бацмов распространены на территории общей площадью 23,0 тыс. га, в окрестностях города Севастопомь, центрацьной и восточной частях Белогорского района, а также вАоль юго-восточного побережья Крыма. В северных частях равнинного Крыма, восточной части Нижнегорского и Советского районов, на юге ЗапаАного преАгорно-приморского района широко распространены почвы, имеющие бонитет 61-70 баммов (25,1\% от общей площади). Также эти почвы с достаточно высоким плодородием занимают территории предгорных районов: Бахчисарайского, Симферопольского и Белогорского.

Почвы с оценкой 60 и менее бамлов мамопригоАны ими вообще непригодны Амя получения высококачественного винограда. В Аанную категорию попали засолённые, переув ажнённые и маломощные почвы. Они составцяют $26,7 \%$ от общей пмощади обследованных территорий. К наиболее критическим территориям Аця ведения промышиенной культуры винограАа возможно отнести прибрежную северную, северо-восточную части, отАемьные участки преАгорных районов южной и юго-западной частей Крымского полуострова, а также значительные массивы на территории Керченского полуострова.

\section{Заключение}

Проведена оценка почвенных условий Крымского полуострова применительно к культуре винограда. Установлено, что 73,4\% обследованных земель пригодны Аля ведения промышленной культуры винограАа, ориентированной на получение высококачественной продуКции. Исходя из провеАенного анациза, можно сАелать вывоА, что наиболее благоприятные почвенные условия Аля развития виноградарства сложимись в Южнобережной зоне, центрацьной части предгорного района, центрацьных степных, западных и юго-западных районах Крымского полуострова. В прибрежной северной, северо-восточной части, на отАельных участках предгорных районов южной и югозападной частей Крымского полуострова, а также на значитемьных массивах Керченского полуострова сло-

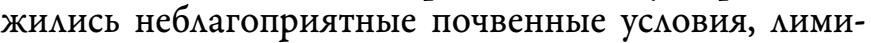
тирующие эффективное выращивание промышленной культуры винограда.

\section{Источники финансирования}

Работа выполнена в рамках государственного заАания № ГР 0833-2015-0009.

\section{Finansing source:}

The study is carried out under public assignment № GR 0833-2015-0009.

\section{Конфликт интересов}

Авторы статьи подтверАици отсутствие конфиикта интересов, о котором необходимо сообщить.

\section{Conflict of interests}

Not declared

\section{Список литературы/References}

1. Баламирзоев М.А., Мирзоев Э.М-Р., Аджиев А.М., Муфараджиев К.Г. Почвы Дагастана. Экологические аспекты их рационального использования. - Махачкала. - 2008. - 335 c.

[Balamirzoev M.A., Mirzoev E.M-R., Adzhiev A.M., Mufaradzhiev K.G. Pochvy Daga-stana. Ekologicheskie aspekty ih racional'nogo ispol'zovaniya. [Soils of Dagestan. Ecological aspects of their efficient use.] Mahachkala. 2008. 335 p. (in Russian)]

2. Иванченко В.И., Тимофеев Р.Г., Баранова Н.В., Рыбалко Е.А. Оценка теплообеспечености и морозоопасности земель Предгорного отделения ГП АФ "Магарач" в контексте перспектив развития промышленного виноградарства. "Магарач". Виноградарство и виноделие. - 2010. - № 1. - C. 10-11.

[Ivanchenko V.I., Timofeyev R.G., Baranova N.V. Assessment of heat supply and frost susceptibility of the piedmont soils of the State Enterprise Agro-farm Magarach in the context of industrial viticulture development potential. Magarah. Viticulture and Winemaking. 2010. № 1. pp. 10-11. (in Russian)]

3. Перстнев Н.Д. Виноградарство. - Кишинёв, 2001.

[Perstnev N.D. Vinogradarstvo [Viticulture]. Kishinyov, 2001. (in Russian)]

4. Акчурин А.Р., Костенко И.В., //Труды Никитского ботанического сада. - 2008. - Т. 130. - С.16-24.

[Akchurin A.R., Kostenko I.V. Trudy Nikitskogo botanicheskogo sada. [Collection of scientific works of Nikitsky Botanical gardens]. 2008. V. 130. pp.16-24. (in Russian)]

5. Рабаданов Г.Г. Почвенный фактор как основа адаптивно-ландшафтной оптимизации размещения виноградных насаждений // Научные труды ГНУ СКЗНИИСиВ. Т.3. 2013, C. 90-93.

[Rabadanov G.G. Pochvennyj faktor kak osnova adaptivnolandshaftnoj optimiza-cii razmeshcheniya vinogradnyh nasazhdenij [Soil factor as a basis for adapted landscape optimization of vineyards placement]. Nauchnye trudy GNU SKZNI$I S i V$. [Scientific works of GNU SKZNIISiV] V.3. 2013, pp. 90-93. (in Russian)]

6. Гаджиев С.А., Кахраманов С.Г. Практическое использование и значение моделей плодородия почв виноградных угодий / Вестник Алтайского государственного аграрного университета. - № 2 (148) . - 2017 . - С. 37 - 44.

[Gadzhiev S.A., Kahramanov S.G. Prakticheskoe ispol'zovanie $i$ znachenie modelej plodorodiya pochv vinogradnyh ugodij [Practical use and importance of soil fertility models of the vineyards]. Vestnik Altajskogo gosudarstvennogo agrarnogo universiteta [Bulletin of Altai State Agrarian University]. № 2 (148) . 2017 . pp. 37 - 44. (in Russian)]

7. Казиев М-Р.А, Аличаев М.М. Почвенные ресурсы Предгорной провинции Дагестана для развития виноградарства//Виноделие и виноградарство. - 2015. - №1 .- C.38-40.

[Kaziev M-R.A, Alichaev M.M. Pochvennye resursy Predgornoj provincii Dagesta-na dlya razvitiya vinogradarstva [Soil resources of the piedmont province of Dagestan for the development of viticulture. Vinodelie $i$ vinogradarstvo [Winemaking and Viticulture ]. 2015. №1. pp. 38-40. (in Russian)]

8. Иванов В.Д., Кузнецова Е.В. Оценка почв: Учебное пособие. - Воронеж: ФГУ ВПО ВГАУ. - 2004. - 287 с.

[Ivanov V.D., Kuznecova E.V. Ocenka pochv: Uchebnoe posobie. [Soil assessment: study guide]. Voronezh: FGU VPO VGAU. 2004. 287 p. (in Russian)]

9. Авидзба А.М., Иванченко В.И., Баранова Н.В., Рыбалко Е.А., Влияние агроклиматических факторов на продуктивность винограда в Бахчисарайском районе АР Крым на примере ГП АФ «Магарач» . - 2009.-19 с. 


\section{ВИНОГРАДАРСТВО}

Оценка почвенных условий крымского полуострова применитемьно к культуре винограда.

[Avidzba A.M., Ivanchenko V.I., Baranova N.V., Rybalko E.A., Vliyanie agroklimaticheskih faktorov na produktivnost' vinograda v Bahchisarajskom rajone AR Krym na pri-mere GP AF Magarach. [The agroclimatic factor impact on grapevine productivity in Bakchisaray region] - 2009.-19 p. (in Russian)]

10. Оптимизация размещения столовых сортов винограда в зависимости от агроэкологических ресурсов АР Крым: Тематический сборник / В.И. Иванченко, Н.В. Баранова, С.П. Корсакова, Е.А.Рыбалко. - Ялта: НИВиВ «Магарач», 2010. -60 c.

[Ivanchenko V.I., Baranova N.V., Korsakova S.P., Rybalko E.A.. Optimizaciya razmeshcheniya stolovyh sortov vinograda $v$ zavisimosti ot agroekolo-gicheskih resursov AR Krym: Tematicheskij sbornik [Table grapevine cultivar placement optimization depending on agro-ecological resources of the Autonomous Republic of Crimea: subject collection]. Yalta: NIViV Magarach, 2010. - 60 p. (in Russian)]

11. Драган Н.А. Почвенные ресурсы Крыма // Научная монография. - 2-е изд., доп. - Симферополь: Доля. 2004. - 208c.

[Dragan N.A. Pochvennye resursy Kryma [Soil resources of Crimea]. Nauchnaya monografiya [Scientific monograph] - 2-d ed. extended- Simferopol': Dolya. 2004. - 208p. (in Russian)]

12. Кизяков Ю.Е., Гусев П.Г., Половецкий И.Я.и др. / Почвенные ресурсы Крыма и пути их рационального использования при эколизации земледелия // Основные направления развития с/х производства Крыма в период перехода к рынку. Сб. научн. Тр. Крымский СХИ-Киев, 1991. - C.48-49.

[Kizyakov Yu.E., Gusev P.G., Poloveckij I.YA.i dr. / Pochvennye resursy Kryma i puti ih racional'nogo ispol'zovaniya pri ekolizacii zemledeliya. Osnovnye napravleniya razvitiya $\mathrm{s} / \mathrm{h}$ proizvodstva Kryma v period perekhoda k rynku. Sb. nauchn. $\operatorname{Tr}$. [Soil resources of Crimea and their effective use under nature friendly agriculture. Major trends in the development of the agriculture of Crimea during the transition to market economy. Collection of works. Krymskij SKHI-Kiev, 1991. pp. 48-49. (in Russian)]

13. Урсу А.Ф., Синкевич 3.А., Хижек В.Е., Марков И.В. Исследование и агроэкологическая оценка почв под сады и виноградники // Почвы Молдавии, Т.3. Кишинев. «Штиинца», - 1986. -с.56-87.

[Ursu A.F., Sinkevich Z.A., Hizhek V.E., Markov I.V. Issledovanie $i$ agroekologi-cheskaya ocenka pochv pod sady $i$ vinogradniki. Pochvy Moldavii [The study and agro-ecological assessment of soils for orchards and vineyards. The soils of Moldova], V.3. Kishinev. Shtiinca, 1986. pp. 56-87. (in Russian)]

14. Крупеников И.А., Подымов Б.П. Классификация и систематический список почв Молдавии: Кишинев. «Штиинца» 1987. - 160 c.

[Krupenikov I.A., Podymov B.P. Klassifikaciya i sistematicheskij spisok pochv Moldavii [Classification and class list of Moldovan soils]: Kishinev. Shtiinca, 1987. - 160 p. (in Russian)]
Рыбалко Е.А., Баранова Н.В.,

Борисова В.Ю.

15. Лунева Р.И. Качественная оценка почв для промышленного виноградарства. Кишинев.: Штиинца. 1981. - 82с.

[Luneva R.I. Kachestvennaya otsenka pochv dlya promyshlennogo vinogradarstva [Soil quality assessment for industrial viticulture]. Kishinev: Shtiinca. 1981. - 82p. (in Russian)]

16. Кисель М.Ф. Основы ампелоэкологии. Кишинев. - 2005. - 336 c.

[Kisel' M.F. Osnovy ampeloekologii. [Basics of ampelo-ecology]. Kishinev. - 2005. - 336 p. (in Russian)]

17. Becker, N.J., Recherches expérimentales sur l'influence du microclimat sur la composition des baies de raisin et la qualité de la récolte. International symposium on the quality of the vintage, Cape Town 1977b.

18. Carbonneau, A., De Loth, C. and Smart, R. E., Méthodologie microclimatique utilisable en agrométéorologie ou l'approche de l'écologie quantitative. Vignes Vins, No. spécial, septembre (1982), p. 87-94.

19. Constantinescu, G., Méthodes et principes de détermination des aptitudes viticoles d'une région et du choix des cépages. Bull. O.I.V.441 (1967), 1179-1205.

20. Deng Y., Dixon J.B. Soil Organic Matter and Organic-Mineral Interaction. In: Dixon J.B., Schulze D.G. (Ed.) Soil Mineralogy with Environmental Application. Madison, Wisconsin, USA, 2002 p. 69-115

21. Cornelis van Leeuwen, Jean-Philippe Roby and Laure de Rességuier, Soil-related terroir factors: A review /OENO One, 2018, 52, 2, p.173-188

22. A.R. Graça, João A. Lopes. Near infrared spectroscopy as a tool for intensive mapping of vineyards soil. Precision Agriculture June 2018, Volume 19, Issue 3, p. 445-462

23. D. Cozzolino, W. U. Cynkar, R. G. Dambergs, N. Shah \&P. Smith. Pages 1610-1619. Received 20 Jul 2011, Accepted 20 May 2012, Accepted author version posted online: 25 Jan 2013, Published online: 30 May 2013

24. L. Irimia, C.V. Patriche. Evaluating the ecological suitability of the vineyards, by using geographic information systems (GIS). Cercetări Agronomice în Moldova. Vol. XLIII , No. 1 (141). 2010, p.49-58

25. Иванченко В.И., Рыбалко Е.А., Баранова Н.В., Ткаченко О.В., Твардовская Л.Б. Оценка виноградарских зон Крыма по почвенным характеристикам для эффективного размещения сортов винограда/Магарач. Виноградарство и виноделие. -2014. - № 1. - С. 16-18.

[Ivanchenko V.I., Rybalko E.A., Baranova N.V., Tkachenko O.V., Tvardovskaya L.B. Otsenka vinogradarskih zon Kryma po pochvennym harakteristikam dlya effektivnogo razmeshcheniya sortov vinograda [Assessment of the viticultural zones of Crimea by their soil characteristics for effective placement of grapevine cultivars]. Magarach. Vinogradarstvo $i$ vinodelie [Magarach. Viticulture and winemaking]. 2014. № 1. pp. 16-18. (in Russian)]

ORCID ID:

Рыбалко E.A. https://orcid.org/0000-0002-4579-3505

Баранова H.B. https://orcid.org/0000-0002-2588-360X

Борисова B.Ю. https://orcid.org/0000-0002-7757-9669 